\title{
Campylobacter Jejuni Increases Transcribed II-1B and Causes Morphometric Changes in the Ileal Enterocytes of Chickens
}

\section{-Author(s)}

\section{Fonseca $\mathrm{BB}^{\prime}$}

Ferreira Júnior $A^{\prime \prime}$

Santos JP dos ${ }^{\vee}$

Coelho LR'

Rossi DA'

Melo RT'

Mendonça EPI

Araújo TG"II

Alves RN"

Beletti ME"

Faculdade de Medicina Veterinária - UFU

" Centro de Microscopia Eletrônica - ICBIM UFU

III Laboratório de Genética - Instituto de Genética e Bioquímica - UFU

Iv Programa de Pós-graduação em Sanidade e Produção Animal nos Trópicos - Universidade de Uberaba (UNIUBE)

Curso de Medicina Veterinária - UNIUBE

\section{Mail Address}

Corresponding author e-mail address

Álvaro Ferreira Júnior

Av. Nenê Sabino, 1801 - Bairro

Universitário - Uberaba/MG - Brasil -

38.055-500

Phone: (34) 3319-8913

E-mail: alvaroferreirajr@gmail.com

\section{-Keywords}

Campylobacter jejuni, chicken, explants TGF- $\beta 3$, IL-1 $\beta$.

\section{ABSTRACT}

Campylobacteriosis is a worldwide foodborne zoonosis disease caused by Campylobacter jejuni. This microorganism is considered a commensal bacterium in chicken hosts. C. jejuni produces epithelial cell modifications and induces a cytokine gene transcription innate immunity repertoire. In the present study, we describe the invasiveness, morphological cellular modifications, and transcript level expressions of innate immune cytokines from $C$. jejuni-inoculated chicken ileum explants. C. jejuni was internalized by epithelial ileum cells at 15 minutes postinoculation (p.i.) and was detected intracellularly for 4 hs (p.i.). Inoculated explants displayed significant increases in cell height. C. jejuni induced a significant elevation of Transforming Growth Factor Beta 3 (TGF- $\beta 3$ ) and Interleukin-1 $\beta$ (IL-1 $\beta$ ) transcripts. In conclusion, C. jejuni is internalized in explanted epithelial ileum cells, produces morphological cell modifications, and induces gene transcription of both anti-inflammatory and pro-inflammatory cytokines.

\section{INTRODUCTION}

Campylobacteriosis is a worldwide foodborne bacterial zoonosis caused by Campylobacter jejuni (De Perio et al., 2013; Guyard-Nicodème et al., 2015). Contaminated chicken meat is the most common source of human infection by C. jejuni bacteria (De Carvalho et al., 2013). The human disease is characterized by a robust intestinal inflammatory response with bloody, watery diarrhoea (Sjöling et al., 2015). Despite its commensal behaviour in chicken hosts, $C$. jejuni is able to invade the cytoplasm of poultry enterocytes and survive in the mucus layer at the brush border of epithelia (Van Deun et al., 2008). C. jejuni-induced modifications of the enterocyte microvillus or mucosal crypts were described after experimental infection (Awad et al., 2015).

It has been demonstrated that both the addition of $C$. jejuni antigens to primary cell cultures of chicken embryo intestines (Li et al., 2008) and inoculation of these antigens in live chickens (Barjesteh et al., 2013; Humphrey et al., 2014) cause inflammatory response and early elevation of the innate immune response of cytokine mRNA expression. Among chicken cytokines, Interleukin-1 $\beta$ (IL-1 $\beta$ ) has pro-inflammatory effects, while the Transforming Growth Factor- $\beta$ (TGF- $\beta$ ) has anti-inflammatory properties (Schat, Kaspers, \& Kaiser, 2014).

Animal intestinal explants have been used to investigate the relationship between luminal bacteria and the gastrointestinal immune system (Low et al., 2006; Skoczek et al., 2014). Human explant models were used for the determination of cell damage and the expression of pro-inflammatory cytokines in colitis studies and for the investigation of the interaction between enteropathogenic bacteria, such as Salmonella typhimurium and C. jejuni, and the host immune system (Haque et al., 
Fonseca BB, Ferreira Júnior A, Melo RT, Mendonça EP, Araújo TG, Santos JP dos, Coelho LR, Rossi DA, Alves RN, Beletti ME

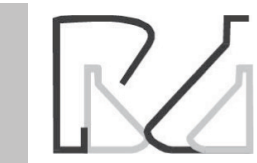

2004; Harvey et al., 2014). C. jejuni behaviour and the chicken innate immune response to this agent have been described by the examination of the intestinal sections of experimentally-infected live chickens (Lamb-Rosteski et al., 2008). Attempts to investigate the most significant age of the chicken host for $C$. jejuni infection (2 to 3 weeks old) could be relevant for focusing on 3-week-old chickens (Chaloner et al., 2014).

In this study, we investigated whether $C$. jejuni could be internalized by the host cell, cause morphological alterations in epithelial cells, and induce the transcription of cytokine genes of the innate immunity repertoire in the experimentally C. jejuni-infected chicken ileum explants.

\section{MATERIAL AND METHODS}

\section{Chicken and ileum explants}

Four 25-day-old specific pathogen free (SPF) broilers, tested negative for $C$. jejuni, were euthanized for the collection of ileum explants. Explants were inoculated with the C. jejuni strain IAL2383 (Fonseca et al., 2014) at a dose level of $2 \times 10^{7} \mathrm{CFU}$, diluted in saline solution at a final volume of $100 \mu \mathrm{L}$. The control was inoculated with $100 \mu \mathrm{L}$ of the saline solution. All the experiments were performed in triplicate. This study was approved by the Ethics Committee on the Use of Animals (CEUA) of the Universidade Federal de Uberlândia (Minas Gerais, Brazil), number 057/09 and number 323/09.

\section{Invasiveness}

The invasiveness assay was carried out as previously described (Van Deun et al., 2008). C. jejuniinoculated ileum explants were evaluated 15, 30, and 60 minutes (min.) and 2 and 4 hs post-inoculation (p.i.). Non-internalized bacteria were removed by successive washing procedures or by treatment with the antibiotic gentamicin $(100 \mu \mathrm{g} / \mathrm{mL})$. Internalized bacteria were recovered by the permeabilization of the cytoplasmic membrane with $1 \%$ Tritom-X-100. $C$. jejuni quantification was performed using real-time PCR (BaxÖSystem, DuPont, USA).

\section{Morphological epithelial cell alterations}

Morphological epithelial cell alterations were detected in C. jejuni-inoculated ileum explants at 15 and 60 minutes p.i. Explants were processed by histology and stained with eosin-haematoxylin. Enterocyte morphology and morphometry were evaluated by optical microscopy at 1000x magnification (Olympus
Campylobacter Jejuni Increases Transcribed II-1B and Causes Morphometric Changes in the Ileal Enterocytes of Chickens

BX 40 microscope, USA). Morphometric analyses were performed using Image HL software (Western Vision Software, USA).

\section{Cytokine transcripts}

Transcripts of cytokines and chemokines (IL-1 $\beta$, IL-8, IL-6, Transforming Growth Factor-2 [TGF-2] and CXCL2) were quantified using quantitative real-time $P C R(q P C R)$ and reverse transcription at 15, 30, and 60 minutes, and 2 and 4 hs (p.i.). For detection of complementary DNA (cDNA) from the RNA transcript, $P C R$ was performed in real time for each gene using as a reference to the endogenous gene beta actin.

\section{Statistical analysis}

The data were statistically analysed using oneway analysis of variance (ANOVA) and Tukey's test. A p-value $\leq 0.05$ was considered significant.

\section{RESULTS AND DISCUSSION}

C. jejuni bacteria were internalized by the epithelial cells of the $C$. jejuni-inoculated chicken ileum explants during the first $15 \mathrm{~min}$ (p.i.) and the concentration of intracellular bacteria (log CFU/g) was unaltered throughout the invasiveness experiment (Figure 1). The dynamics of $C$. jejuni invasion in cultured human cells (De Melo, Gabbiani, \& Pechère, 1989) includes bacterium adherence to the host cell surface and internalization of bacteria around $1 \mathrm{~h}$ (p.i.), as well as intracytoplasmic bacteria during the interval of time from $3 h$ to $9 h$ (p.i.). Additionally, it was demonstrated that $C$. jejuni has the ability to invade different cultured cell lines and that its

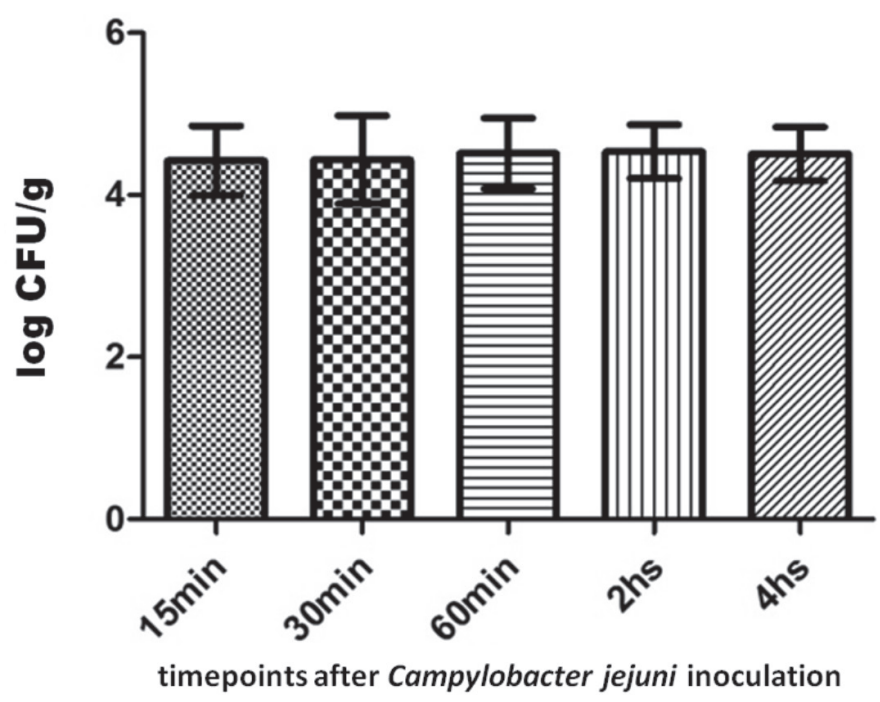

Figure 1 - Dynamics of bacterium invasiveness in Campylobacter jejuni-infected chicken ileum explants at different times post infection. 
invasiveness is dependent on the host species (Aguilar et al., 2014). Our results corroborate the occurrence of bacterium internalization in cultured primary chicken cells, as previously described (Byrne, Clyne, \& Bourke, 2007), and may suggest that chicken ileum explants could be an alternative method to investigate $C$. jejuni invasiveness. Curiously, although mucin proteins in chicken intestines reduces $C$. jejuni internalization by the host cell (Alemka et al., 2010), that phenomenon was apparently not impaired in the C. jejuni-inoculated chicken ileum explants.

There was a significant increase in the height of epithelial cells in the C. jejuniinoculated ileum explants (Figure 2). We did not detect disruptions in

A

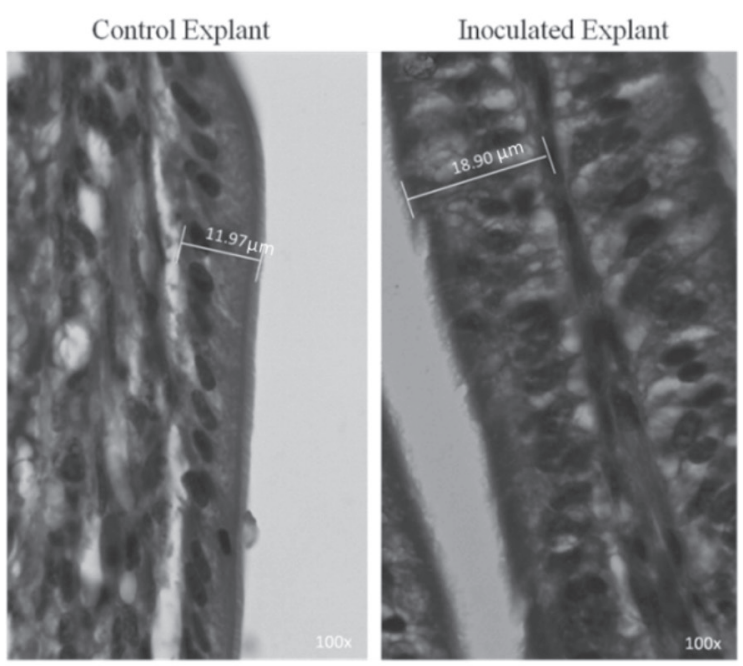

60 minutes after Campylobacter jejuni inoculation the structure of the microvilli or crypts (Figure 2). In vitro, the inoculation of $C$. jejuni in the cell monolayer has been shown to increase paracellular permeability and the transepithelial flux of the cultured cells (LambRosteski et al., 2008). Additionally, C. jejuni disrupts intercellular junctions, increasing the width of the infected cells compared with the controls (Wine, Chan, \& Sherman, 2008). Cytolethal Distending Toxin (CDT) induces a cytoplasmic distension and leads to cell death (Jeon, Itoh, \& Ryu, 2005). It seems that the epithelial cell modification observed in the inoculated chicken ileum explants was an effect of bacterium on cells.

In the present study, we showed a significant elevation of TGF- $\beta 3$ and IL1 $\beta$ mRNA transcript

B

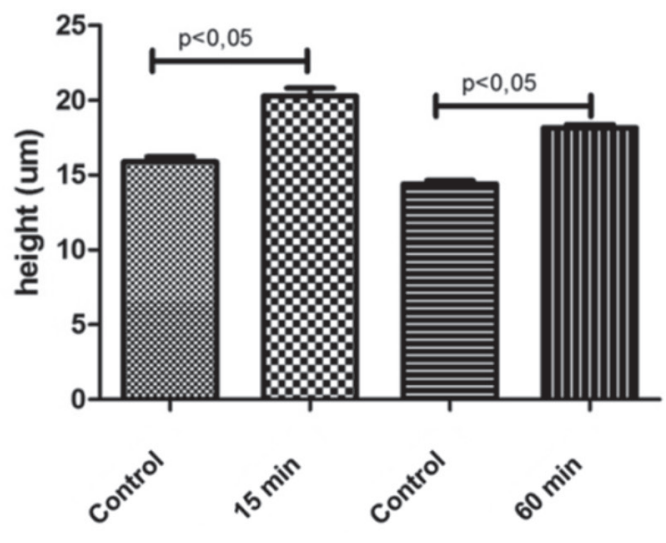

timepoints after Campylobacter jejuni inoculation

Figure 2 - Morphometry from inoculated explants: (A) micrography of Campylobacter jejuni-inoculated chicken ileum explants at 60 minutes postinfection; (B) average of epithelial cell height from C. jejuni-inoculated chicken ileum explants at two different times.

levels, which reached a peak at 15 min and 4 h (p.i.), respectively (Figure 3 ). No statistical difference was found in the transcript levels of IL-6, IL-8, or of CXCL1 and CXCL2 mRNA transcripts. Bacterial pathogenassociated molecular patterns (PAMPs) recognized by pathogen recognition receptors (PRRs), which are expressed by intestinal epithelial cells, result in cytokine gene transcription (IL-1 $\beta, I L-6, I L-8$ and chemokynes) from the innate immune repertoire (Keeler et al., 2007; Wigley, 2013). Interestingly, disrupted or live C. jejuni bacteria have been shown to have different effects on the activation of the PRRs signalizing pathways (AlSayeqh et al., 2010; De Zoete et al., 2010). Smith et al. (2005) and Li et al. (2008) described an elevated expression of the proinflammatory cytokines IL$1 \beta, I L-6, I L-8$ transcript levels in cultured avian cells infected with C. jejuni. In this context, the live C. jejuni could apparently activate innate immunity signalling pathways in chicken ileum explants.

Commensal bacteria have the ability to suppress the expression of anti-inflammatory cytokine mRNA (i.e. TGF- $\beta$ ) and also reduce pro-inflammatory (i.e., IL$1 \beta)$ cytokines, whereas pathogenic bacteria increase both pro-inflammatory and anti-inflammatory cytokine mRNA (Bahrami, Macfarlane, \& Macfarlane, 2011). In this sense, $C$. jejuni cannot be regarded as merely a gut commensal bacterium because the infection of broiler chickens has been clearly associated with intestinal inflammation (Humphrey et al., 2014). Additionally, the anti-inflammatory or pro-inflammatory cytokine mRNA levels display different concentrations according to the nature of the $C$. jejuni antigen preparation (Al- 


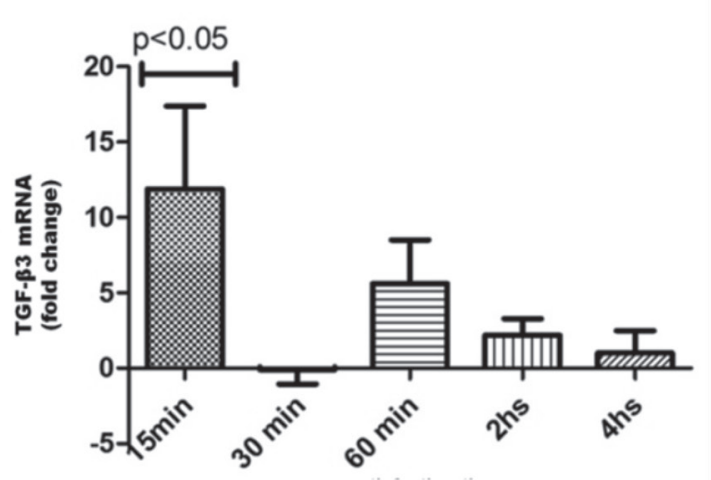

timepoints after Campylobacter jejuni inoculation

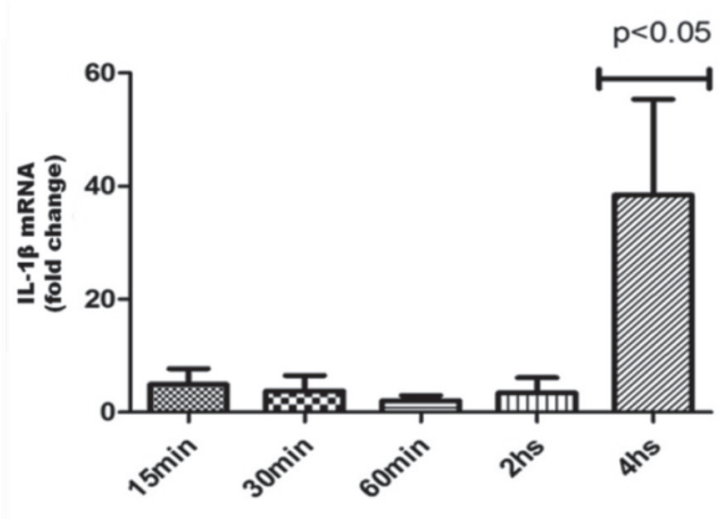

timepoints after Campylobacter jejuni inoculation

Figure 3 - Relative quantitation of transcript levels of TGF- $\beta 3$ and IL-1 $\beta$ mRNA in C. jejuni-inoculated chicken ileum explants at different times.

Amri et al., 2008). In the present study, live C. jejuni may have induced cytokine gene transcription similarly to pathogenic bacteria.

In conclusion, C. jejuni can be internalized by chicken ileum cells, causes morphological cell modifications, and induces both anti-inflammatory and pro-inflammatory cytokine transcripts.

\section{ACKNOWLEDGEMENTS}

This study was financed by the Research Support Foundation in Minas Gerais, Brazil (FAPEMIG), and the Brazilian Research Support Foundation (CNPq).

\section{REFERENCES}

Aquilar C, Jiménez-Marín Á, Martins RP, Garrido JJ. Interaction between Campylobacter and intestinal epithelial cells leads to a different proinflammatory response in human and porcine host. Veterinary Immunology and Immunopathology 2014;162(1/2):14-23. Available from: http://www.ncbi.nlm.nih.gov/pubmed/25307769.

Al-Amri Al, Botta GA, Tabbara KS, Ismaeel AY, Al-Mahmeed AE, Qareeballa AY, Bin Dayna KM, Bakhiet MO. Campylobacter jejuni induces diverse kinetics and profiles of cytokine genes in INT-407 cells. Saudi Medical Journal 2008;29(4):514-519. Available from: http://www.ncbi.nlm.nih. gov/pubmed/18382790

Alemka A, Whelan S, Gough R, Clyne M, Gallagher ME, Carrington SD, et al. Purified chicken intestinal mucin attenuates Campylobacter jejuni pathogenicity in vitro. Journal of Medical Microbiology 2010;59(8):898903. Available from: http://www.ncbi.nlm.nih.gov/pubmed/20466838.

Al-Sayegh AF, Loughlin MF, Dillon E, Mellits KH, Connerton IF. Campylobacter jejuni activates NF-kappaB independently of TLR2, TLR4, Nod1 and Nod2 receptors. Microbial Pathogenesis 2010;49(5):294-304. Available from: http://www.ncbi.nlm.nih.gov/pubmed/20599492.

Awad WA, Molnár A, Aschenbach JR, Ghareeb K, Khayal B, Hess C, et al. Campylobacter infection in chickens modulates the intestinal epithelial barrier function. Innate Immunology 2015;21(2):151-160. Available from: http://www.ncbi.nlm.nih.gov/pubmed/24553586.

Bahrami B, Macfarlane S, Macfarlane GT. Induction of cytokine formation by human intestinal bacteria in gut epithelial cell lines. Journal of
Applied Microbiology 2011;110(1):353-363. Available from: http:// www.ncbi.nlm.nih.gov/pubmed/21070518.

Barjesteh N, Hodgins DC, St Paul M, Quinteiro-Filho WM, DePass C, Monteiro MA, et al. Induction of chicken cytokine responses in vivo and in vitro by lipooligosaccharide of Campylobacter jejuni HS:10. Veterinary Microbiology 2013;164(1-2):122-130. Available from: http://www.ncbi.nlm.nih.gov/pubmed/23473646.

Byrne CM, Clyne M, Bourke B. Campylobacter jejuni adhere to and invade chicken intestinal epithelial cells in vitro. Microbiology 2007;153(2):561569. Available from: http://www.ncbi.nlm.nih.gov/pubmed/17259628.

Carvalho AF de, Silva DM da, Azevedo SS, Piatti RM, Genovez ME, Scarcelli E. Detection of CDT toxin genes in Campylobacter spp. strains isolated from broiler carcasses and vegetables in São Paulo, Brazil. Brazilian Journal Microbiology 2013;44(3):693-699. Available from: http:// www.ncbi.nlm.nih.gov/pubmed/24516435

Chaloner G, Wigley P, Humphrey S, Kemmett K, Lacharme-Lora L, Humphrey $\mathrm{T}$, et al. Dynamics of dual infection with Campylobacter jejuni strains in chickens reveals distinct strain-to-strain variation in infection ecology. Applied Environmental Microbiology 2014;80(20):6366-6372. Available from: http://www.ncbi.nlm.nih.gov/pubmed/25107966

Fonseca BB, Rossi DA, Maia CA, Nalevaiko PC, Melo RT, Cuccato LP, et a. Characterization of the virulence, growth temperature and antibiotic resistance of the Campylobacter jejuni IAL 2383 strain isolated from humans. Brazilian Journal of Microbiology 2014;45(1):271-274. Available from: http://www.ncbi.nlm.nih.gov/pubmed/24948944.

Guyard-Nicodème M, Rivoal K, Houard E, Rose V, Quesne S, Mourand G, et al. Prevalence and characterization of Campylobacter jejuni from chicken meat sold in French retail outlets. International Journal of Food Microbiology 2015:203:8-14. Available from: http://www.ncbi.nlm. nih.gov/pubmed/25770428.

Haque A, Bowe F, Fitzhenry RJ, Frankel G, Thomson M, Heuschkel R, et al. Early interactions of Salmonella enterica serovar typhimurium with human small intestinal epithelial explants. Gut 2004:53(10):1424-1430. Available from: http://www.ncbi.nlm.nih.gov/pubmed/15361488.

Harvey BS, Sia TC, Wattchow DA, Smid SD. Interleukin 17A evoked mucosal damage is attenuated by cannabidiol and anandamide in a human colonic explant model. Cytokine 2014;65(2):236-244. Available from: http://www.ncbi.nlm.nih.gov/pubmed/24238999.

Humphrey S, Chaloner G, Kemmett K, Davidson N, Williams N, Kipar A, et al Campylobacter jejuni is not merely a commensal in commercial broiler chickens and affects bird welfare. mBio 2014;5(4):e01364-0114. Available from: http://www.ncbi.nlm.nih.gov/pubmed/24987092. 
Jeon B, Itoh K, Ryu S. Promoter analysis of cytolethal distending toxin genes (cdtA , B, and C) and effect of a luxS mutation on CDT production in Campylobacter jejuni. Microbiology Immunology 2005;49(7):599-603. Available from: http://www.ncbi.nlm.nih.gov/pubmed/16034202.

Keeler CL, Bliss TW, Lavric M, Maughan MN. A functional genomics approach to the study of avian innate immunity. Cytogenetics Genome Research 2007;117(1-4):139-145. Available from: http://www.ncbi. nlm.nih.gov/pubmed/17675854

Lamb-Rosteski JM, Kalischuk LD, Inglis GD, Buret AG. Epidermal growth factor inhibits Campylobacter jejuni-induced claudin-4 disruption, loss of epithelial barrier function, and Escherichia coli translocation. Infection Immunology 2008;76(8):3390-3398. Available from: http:// www.ncbi.nlm.nih.gov/pubmed/18490463.

LI YP, Ingmer $H$, Madsen M, Bang DD. Cytokine responses in primary chicken embryo intestinal cells infected with Campylobacter jejuni strains of human and chicken origin and the expression of bacterial virulence-associated genes. BMC Microbiology 2008;(8):107. Available from: http://www.ncbi.nlm.nih.gov/pubmed/18588667.

Low AS, Dziva F, Torres AG, Martinez JL, Rosser T, Naylor S, et al. Cloning, expression, and characterization of fimbrial operon F9 from enterohemorrhagic Escherichia coli O157:H7. Infection Immunology 2006;74(4):2233-2244. Available from: http://www.ncbi.nlm.nih.gov/ pubmed/16552054.

Melo MA de, Gabbiani G, Pechère JC. Cellular events and intracellular survival of Campylobacter jejuni during infection of $\mathrm{HEp}-2$ cells. Infection Immunology 1989; 57(7):2214-2222. Available from: http:// www.ncbi.nlm.nih.gov/pubmed/2731988.

Perio MA de, Niemeier RT, Levine SJ, Gruszynski K, Gibbins JD. Campylobacter infection in poultry-processing workers, Virginia, USA, 2008-2011. Emerging Infectious Diseases 2013;19(2):286-288. Available from: http://www.ncbi.nlm.nih.gov/pubmed/23347390.
Schat KA, Kaspers B, Kaiser P. Avian immunology. $2^{\text {nd }}$ ed. London: Academic Press; 2014.

Sjöling Å, Sadeghipoorjahromi L, Novak D, Tobias J. Detection of major diarrheagenic bacterial pathogens by multiplex PCR panels. Microbiology Research 2015;172:34-40. Available from: http://www. ncbi.nlm.nih.gov/pubmed/25542594.

Skoczek DA, Walczysko P, Horn N, Parris A, Clare S, Williams MR, et al. Luminal microbes promote monocyte-stem cell interactions across a healthy colonic epithelium. Journal of Immunology 2014;193(1):439 451. Available from: http://www.ncbi.nlm.nih.gov/pubmed/24907348.

Smith CK, Kaiser P, Rothwell L, Humphrey T, Barrow PA, Jones MA Campylobacter jejuni-induced cytokine responses in avian cells. Infection Immunology 2005;73(4):2094-2100. Available from: http:// www.ncbi.nlm.nih.gov/pubmed/15784550.

Van Deun K, Pasmans F, Ducatelle R, Flahou B, Vissenberg K, Martel $A$, et al. Colonization strategy of Campylobacter jejuni results in persistent infection of the chicken gut. Veterinary Microbiology 2008;130(3-4):285-297. Available from: http://www.ncbi.nlm.nih.gov/ pubmed/18187272.

Wigley P. Immunity to bacterial infection in the chicken. Development Comparative Immunology 2013;41(3):413-417. Available from: http:// www.ncbi.nlm.nih.gov/pubmed/23648643.

Wine E, Chan VL, Sherman PM. Campylobacter jejuni mediated disruption of polarized epithelial monolayers is cell-type specific, time dependent, and correlates with bacterial invasion. Pediatric Research 2008;64(6):599-604. Available from: http://www.ncbi.nlm.nih.gov/ pubmed/18679160

Zoete MR de, Keestra AM, Roszczenko P, Putten JP van. Activation of human and chicken toll-like receptors by Campylobacter spp. Infection Immunology 2010;78(3):1229-38. Available from: http://www.ncbi. nlm.nih.gov/pubmed/20038539. 
